Rev. Salud pública. 6 (Sup. 1): 80-96, 2004

REVISIÓN/ REVIEW

\title{
Inmunología del Absceso Hepático Amebiano
}

\author{
DIEGO F. VIASUS PÉREZ ${ }^{1}$, ANÁLIDA E. PINILLA² y MYRIAM C. LÓPEZ ${ }^{3}$ \\ ${ }^{1}$ Médico. Universidad Nacional de Colombia.E-mail: nanoviasus@terra.com.co \\ ${ }^{2}$ Médica. Especialista en Medicina Interna. M. Sc. Educación con Énfasis en Docencia \\ Universitaria. Departamento de Medicina Interna. Facultad de Medicina, Universidad \\ Nacional de Colombia. E- mail: aepinillar@unal.edu.co \\ ${ }^{3}$ Bacterióloga. M. Sc. Microbiología. Especialista Microbiología Médica. Departamento de \\ Salud Pública. Universidad Nacional de Colombia. E-mail: mclopezp@unal.edu.co
}

Recibido 20 Agosto 2004/Enviado para Modificación 17 Septiembre 2004/Aceptado 4 Octubre 2004

\section{RESUMEN}

La infección por el parásito Entamoeba histolytica es causa de disentería y absceso hepático amebianos, enfermedades asociadas con alta morbimortalidad. En el caso de la amebiosis hepática, el papel de la inmunidad humoral en la protección no ha sido del todo establecido pero tiene importancia en estudios seroepidemiológicos y métodos diagnósticos. La inmunidad celular es importante para el control de la infección y desarrollo de inmunidad protectora luego de amebiosis invasiva. Las técnicas de genética molecular y los nuevos modelos de experimentación han enseñado mucho acerca de la patogénesis de la amebiosis, su entendimiento adecuado junto con el conocimiento de la biología molecular y genética del parásito y los mecanismos inmunes del huésped permitirá no sólo el desarrollo de nuevas opciones diagnósticas y de tratamiento sino también de una vacuna efectiva y segura para eliminar la enfermedad.

Palabras Claves: Entamoeba histolytica, absceso hepático amebiano, formación de anticuerpos, inmunidad celular, vacuna (fuente: DeCS, BIREME).

\section{ABSTRACT}

Immunology of the amebic liver abscess

Infection by the parasite Entamoeba histolytica causes amebic dysentery and amebic liver abscess, diseases associated with a high morbidity and 
mortality. In the case of amebic liver infection, the role of humoral immunity in protection has not been well established but it is important in seroidemiological studies and for diagnostic methods. Cellular immunity is important for the control of infection and the development of protective immunity after an invasive infection. Molecular genetic techniques and new experimental models have increased the knowledge on the pathogenesis of amebiasis. Its adequate understanding, together with the knowledge on the molecular biology and genetics of the parasite and of the host's immune

mechanisms will allow the development of new diagnostic and therapeutic tools as well as the development of an effective and safe vaccine for eliminating the disease.

Key Words: Entamoeba histolytica, liver abscess, amoebic, immunity humoral, cell-mediated immunity, vaccine (source: $M e S H, N L M$ ).

$\mathrm{S}$ e realizó una revisión de la inmunología del absceso hepático amebiano. Luego de una búsqueda en MEDLINE, se identificaron artículos publicados desde 1966 hasta el 2003 usando los términos Entamoeba histolytica, absceso hepático amebiano, amebiasis hepática, inmunología, vacuna, patogénesis e inmunoglobulinas en inglés y español. Se identificaron artículos y recursos adicionales como capítulos de libros y resúmenes los cuales fueron revisados en búsqueda de publicaciones relevantes. Todos los artículos incluidos fueron revisados por los autores.

\section{INMUNOLOGIA DEL ABSCESO HEPÁTICO AMEBIANO}

La amebiosis es una enfermedad producida por Entamoeba histolytica de distribución mundial. Se estima que infecta alrededor de 500 millones de personas anualmente y que de ellas 110000 mueren por complicaciones causadas por este agente. El $1 \%$ de las personas infectadas pueden desarrollar patologías potencialmente fatales como la colitis amebiana fulminante o el absceso hepático amebiano-AHA (1). El AHA es resultado de la invasión al hígado por E. histolytica desde un foco intestinal; en la mayoría de los casos existe sólo un absceso localizado generalmente en el lóbulo hepático derecho, el cual recibe la mayor parte de la circulación portal. La frecuencia de AHA es 3 veces mayor en hombres que en mujeres (2).

La morbilidad y la mortalidad no han cambiado en la última década a pesar de la quimioterapia antiamebiana efectiva disponible, en gran parte por prácticas de higiene inapropiadas en regiones donde la prevalencia es alta (36). En Colombia, constituye un problema de salud pública, según las tasas de 
prevalencia de amebiosis de la encuesta nacional de morbilidad de 1980, se encontró que aproximadamente 3025000 colombianos son portadores asintomáticos de E. histolytica y 1075000 han sufrido algún tipo de enfermedad amebiana intestinal o extraintestinal (7).

Sin embargo, en el estudio de 140 muestras realizado por Guzmán y colaboradores en zona rural de Cundinamarca, se encontró que el 16,4 \% de la población presentaba el complejo E. histolytica/E. dispar y utilizando la detección de lectina de adherencia especifica de E. histolytica para diferenciar E. histolytica (especie patógena) de E. dispar, el 8,6\% de portadores asintomáticos corresponden a la especie E. histolytica, lo cual equivale al $1,4 \%$ de toda la población (8).

El absceso hepático amebiano-AHA, es la manifestación extraintestinal más frecuente, típicamente los pacientes se presentan con un cuadro clínico agudo o crónico, con dolor abdominal en hipocondrio derecho asociado a síntomas constitucionales (pérdida de peso, mialgias y malestar general) y fiebre, los síntomas gastrointestinales y la ictericia son raros (9). La complicación más común es su ruptura con extensión a peritoneo, pleura o pericardio, también se han descrito fístulas hepato-bronquiales, absceso pulmonar, derrame pleural reactivo, trombosis de la vena hepática y obstrucción de la vena cava inferior. El diagnóstico de AHA se realiza por un cuadro clínico sugestivo, evidencia imaginológica del absceso (ecografía o TAC), serología positiva para E. histolytica y respuesta al tratamiento con nitroimidazoles $(10-15)$.

En la patogénesis del AHA, los trofozoitos de E. histolytica pueden invadir la mucosa del colon dependiendo de su perfil genético e inmunoenzimático (16). Al ingresar al sistema porta produciendo enzimas proteolíticas y haciéndose resistentes a la lisis por el complemento producen infección extraintestinal, es más frecuente a nivel hepático, en especial en el lóbulo derecho, donde la mayoría de los parásitos serán lisados, sin embargo, algunos sobreviven y desarrollan su actividad histolítica, generando trombosis y microabscesos que posteriormente progresan en tamaño. Estudios anatomopatológicos han demostrado que al llegar los trofozoitos al hígado son rodeados por neutrófilos. La lisis de los neutrófilos y de los histiocitos de la periferia dan origen a la necrosis, estas células son remplazadas progresivamente por macrófagos y células epitelioides hasta desarrollar un granuloma. Lo que indica que el proceso de lisis de los hepatocitos es combinado y se debe tanto a la capacidad histolítica de la ameba como a la lisis de los neutrófilos. En la periferia del absceso se encuentra tejido hepático en destrucción y fibrosis, con linfocitos, plasmocitos y trofozoitos; el contenido, que no es pu- 
rulento, consiste en un líquido de color chocolate o amarillo rojizo, sin trofozoitos, ya que estos no sobreviven al ambiente y generalmente permanece estéril, excepto cuando ocurre una infección secundaria. En los abscesos crónicos, puede constituirse una cápsula de tejido fibroso que los aísla del tejido sano $(5,17)$.

En los últimos años, las técnicas de genética molecular y los nuevos modelos de experimentación han enseñado mucho acerca de la patogénesis de la amebiosis, pero a pesar de su importancia, persisten interrogantes acerca de la respuesta inmune frente a la infección por este parásito (4). Hallazgos característicos en la inmunidad celular y humoral han sido detectados en pacientes con enfermedad invasiva.

\section{INMUNIDAD HUMORAL}

No hay duda que la infección por E. histolytica provoca una respuesta humoral, los anticuerpos son producidos en amebiosis sintomática pero también en amebiosis asintomática probablemente como resultado de invasión subclínica controlada $(18,19)$.

Se ha demostrado el aumento de anticuerpos circulantes en pacientes con AHA, predominantemente la IgG que puede detectarse una semana luego de iniciados los síntomas en humanos y animales de experimentación (20). Estos anticuerpos, principalmente la IgG, persisten años después de resuelta la amebiosis invasiva $(9,21,22)$ probablemente por la persistencia de antígenos amebianos en las células del sistema monocito macrófago (19).

Luego de 2 a 6 semanas, del inicio de los síntomas, la IgG puede ser detectada por diferentes métodos (23). Los títulos elevados no se relacionan con la severidad clínica o pronóstico, pero coinciden con estadios tempranos de la enfermedad, los cuales con el tratamiento caen a velocidades variables. Análisis estadísticos indican relación entre amebiosis activa y aumento de la concentración de IgG, los pacientes con AHA muestran niveles más altos de IgG que aquellos con colitis amebiana o pacientes sanos $(\mathrm{p}<0,001)$ $(21,24,25)$.

En estudios seroepidemiológicos el 81-100 \% de los pacientes con AHA y un porcentaje menor $(50 \%)$ de pacientes con colitis amebiana $(23,24,26)$ desarrollan IgG específica para E. histolytica. Un bajo porcentaje de falsos negativos puede ser debido al desarrollo tardío en la producción de anticuerpos y resultados falsos positivos se encuentran más frecuentemente en áreas 
endémicas por infecciones pasadas (18). En síntesis, de todas las inmunoglobulinas, la $\operatorname{IgG}$ ha sido la más consistente en pacientes con amebiosis sintomática (25).

La IgA y IgE séricas también pueden aumentarse aunque en menor grado, no muestran correlación con amebiosis invasiva (AHA o colitis amebiana), siendo sus valores séricos similares con los de pacientes asintomáticos ( $\mathrm{p}>0,1$ para $\operatorname{IgA}$ ) y con patrones diferentes de evolución luego del tratamiento. En otro estudio un $83 \%$ de pacientes desarrolló IgA y un $10 \% \operatorname{IgE}$ séricas. Niveles elevados de IgM se correlacionan con pacientes con AHA $(\mathrm{p}<0,01)$, pero no en pacientes con colitis amebiana comparados con controles ( $\mathrm{p}>0,1)$; sin embargo, en otro estudio se encontró IgM específica contra lectina de adhesión hasta en el $45 \%$ de pacientes con colitis amebiana (25-27).

Niveles elevados de IgA secretoria se encuentran en pacientes con AHA, tanto en pacientes con enfermedad aguda como en pacientes con enfermedad ya tratada hasta 8 meses previos $(p<0,002)(28)$. Esta inmunoglobulina se ha encontrado en saliva, leche materna y heces de pacientes con amebiasis invasiva. La IgA secretoria bloquea la adherencia de trofozoitos a las células epiteliales intestinales, se ha destacado su papel protector en resistencia a la reinfección, aunque de manera transitoria. Un estudio reciente demostró que niños con IgA secretoria en el tracto gastrointestinal tienen en un $64 \%$ menos infecciones por el parásito al compararse con pacientes que no la presentan, en contraste la IgG no fue relacionada con protección $(4,29)$. Se ha visto que las cisteinproteasas de la E. histolytica degradan tanto la IgA como la IgG, lo cual puede limitar la efectividad de la respuesta humoral del huésped (30).

Es necesario recordar la regulación de las cascadas del complemento que ha evolucionado para permitir una activación muy rápida y auto amplificada lo cual es necesario para una defensa eficaz contra la infección al igual que una regulación fina del sistema (31). Es así como, el suero de pacientes con amebiosis invasiva previa o pacientes infectados que tienen títulos altos de anticuerpos contra el trofozoito de E. histolytica es amebicida a través de activación del complemento; en algunos pacientes con AHA se encuentran niveles bajos de $\mathrm{C} 3$ y normales de $\mathrm{C} 1$, un hallazgo que sugiere activación de la vía alterna del complemento (24), generando componentes que pueden lisar la E. dispar y a los cuales escapa la E. histolytica su resistencia esta dada en virtud a la lectina de adhesión que tiene reactividad cruzada antigénica con la proteína CD59 de las células sanguíneas, proteína reguladora del complemento, al inhibir la inserción en la membrana de C9 (30). 
Esta proteína CD59 también denominado inhibidor de membrana de la lisis reactiva, es el principal inhibidor de membrana del complejo de ataque de membrana (estructura de poros liposoluble que produce la lisis osmótica de las células). Su presencia en las membranas de las células del huésped (eritrocitos, linfocitos, monolitos, neutrófilos, plaquetas, células endoteliales, células epiteliales) y su ausencia en las superficies de los agentes infecciosos (bacterias, protozoos) da lugar a una inhibición selectiva de la activación del complemento en las células del huésped pero no en los microorganismos, así el sistema de complemento distingue entre lo propio y lo no propio.

De otra parte, las anafilotoxinas $\mathrm{C} 3 \mathrm{a}$ y $\mathrm{C} 5 \mathrm{a}$ (potentes estimulantes de respuesta inflamatoria) son degradadas por cisteinproteasas amebianas, mecanismos que se han implicado en la patogenia de la amebiosis, considerándose un factor necesario para la invasión o diseminación in vivo $(30,32)$ que se sustenta por estudios experimentales en animales donde el aislamiento de las cepas causantes de AHA son resistentes a lisis mediada por complemento y la inducción de depleción del complemento aumenta la susceptibilidad para desarrollar AHA (24).

La contribución de la respuesta humoral a la inmunidad protectora no ha sido establecida, aparentemente no previene infecciones posteriores que pueden ocurrir inclusive con títulos altos de anticuerpos, esto es sorprendente dado que estudios en ratones inmunodeficientes y realizando transferencia pasiva de anticuerpos contra proteína rica en serina de E. histolytica, lipofosfoglicanos y lectina de adherencia han resultado en protección contra la formación de AHA y reducción en tamaño del absceso de $24,5 \%$ a $3,5 \%$ $(\mathrm{p}<0,0001)(29,30,32)$. Además, el suero inmune tiene efectos citolíticos sobre trofozoitos, inhibe su crecimiento, neutraliza la virulencia e inhibe la eritrofagocitosis, lo cual sugiere el papel protector de los anticuerpos, y aunque para algunos autores esto es discutible, lo que no se pone en duda es su valor en el diagnóstico y en estudios epidemiológicos de la amebiosis (20).

Para la detección de anticuerpos se encuentran disponibles varios métodos para el diagnóstico de amebiosis hepática, estas pruebas pueden permanecer positivas por meses o años, según Salata y Ravdin hasta 11 años (24), Petri hasta 20 años (9) y Knobloch y Mannweiler hasta 10 años (23), por lo que es necesario darles valor, dado que una reacción positiva puede corresponder a una infección amebiana pasada (8). Por tanto en zonas de alta endemicidad debe correlacionarse el cuadro clínico del paciente con las pruebas inmunológicas (34), en Colombia la prueba de referencia es el ELISA IgG (35-39). 
En otros estudios de AHA se han determinado niveles de IgM y se ha observado que su presencia no es tan marcada como ocurre con IgG y por tanto no diferencia una infección pasada y de una reciente (40), en el estudio de Pinilla y colaboradores se reporta una sensibilidad de $18 \%$ y especificidad de $100 \%$ para un punto de corte de 0,511 de ELISA IgM (41), otro estudio utilizando detección de IgM específica contra lectina de adhesión tiene mayor sensibilidad $^{(42)}$.

Es importante tener en cuenta que mediante las técnicas de biología molecular y recientemente con detección de antígenos de la E. histolytica, por medio de coaglutinación, ELISA o reacción en cadena de la polimerasa en suero se puede diferenciar una infección reciente de una pasada con reportes de sensibilidad y especifidad mayores del $90 \%(15,43-45)$ (Tabla 1), pero hasta ahora están todavía en investigación en otros países y no están al alcance de todas las comunidades científicas por lo que no pueden ser utilizadas cotidianamente en nuestro medio.

Tabla 1. Pruebas diagnósticas para absceso hepático amebiano

\begin{tabular}{lcc}
\hline Prueba & Sensibilidad & Especificidad \\
\hline ELISA IgG (35-39) & $74,7-100$ & $91-100$ \\
ELISA IgM $^{*}(41,42)$ & $18-91$ & $95-100$ \\
$\mathrm{RCP}^{\dagger}(15)$ & $33-100$ & 96 \\
Antígenos en suero $^{\ddagger}(43,45)$ & $90-96$ & \\
\hline RCP: Reacción en Cadena de la Polimerasa; * Los valores de sensibilidad y espe- \\
cificidad varían de acuerdo a si se utiliza; detección de anticuerpos específicos co- \\
ntra lectina de adherencia o no; ${ }^{\dagger}$ Detección de secuencias de DNA o rRNA del pa- \\
rásito en el líquido del AHA; ${ }^{\ddagger}$ Permite diferenciar entre enfermedad pasada y re- \\
ciente y seguimiento de la respuesta al tratamiento
\end{tabular}

\section{INMUNIDAD CELULAR}

Como se observa en la Figura 1, la invasión tisular por la E. histolytica induce supresión de la respuesta inmune celular y a pesar de la infiltración de células inflamatorias la ameba prolifera en el absceso hepático. La supervivencia de los trofozoitos puede ser favorecida por el desarrollo de un estado transitorio de inmunosupresión, asociado con la amebiosis hepática y demostrada a nivel celular por deficiencias en la función de macrófagos y linfocitos $\mathrm{T}$ durante la infección y en respuesta a proteínas solubles de la ameba in vitro, muchos de estos mecanismos continúan en investigación (3). Hay 
evidencia que la respuesta celular en la infección amebiana está relacionada con inmunidad protectora la cual emerge luego de la recuperación de la amebiosis invasiva (18).

La modulación de la función de los macrófagos es multifactorial, tienen gran actividad amebicida cuando son activados in vitro por interferón gamma (INF $\gamma$ ), factor de necrosis tumoral alfa (FNT $\alpha$ ), lipopolisacáridos y factor estimulante de colonias 1 (FEC-1) y en la infección por E. histolytica se asocia con alteración en su función (3), la ameba patógena causa lisis directa de los macrófagos y otras células.

Varios estudios in vivo e in vitro han evidenciado alteración en la función efectora y accesoria de los macrófagos, los cuales se vuelven refractarios a la activación por interferón gamma y lipopolisacáridos, está reducida la habilidad para presentar antígenos a linfocitos T por disminución en la expresión del complejo mayor de histocompatibilidad II, aumento en la producción de metabolitos del ácido araquidónico principalmente la prostaglandina E2, leucotrienos C4 y B4 que disminuyen la producción de proteínas y promueven la formación de granulomas, defectos en la producción de interleuquinas y FNT $\alpha$ (necesarios para la formación de oxido nítrico, activación de granulocitos, fibroblastos, macrófagos y adherencia y migración de neutrófilos), modulación en la producción de metabolitos oxidativos $\left(\mathrm{H}_{2} \mathrm{O}_{2}, \mathrm{O}_{2}{ }^{-}\right)$y no oxidativos (oxido nítrico) e inefectividad en la lisis amebiana (3).

Esta supresión en la función del macrófago ocurre en la población próxima al absceso, pues la población periférica no se encuentra afectada, lo cual sugiere que es un evento local relacionado con exposición directa a la ameba o sus productos $(3,30)$. En un reporte de caso de múltiples episodios de AHA en un paciente durante un periodo de 4 años, se encontraron alteraciones en la producción de intermediarios reactivos de oxígeno, mecanismo importante de resistencia por parte de los macrófagos. En este mismo sentido, la depresión de la actividad de macrófagos inducida por sílica o por suero anti-macrófagos incrementa la severidad del AHA y su estimulación con BCG disminuye el daño tisular (46).

Aunque las alteraciones en la función de los linfocitos están menos caracterizadas, tienen un papel importante en la estimulación de macrófagos y activación de células $T$, muestran actividad amebicida directa y producen interleuquina 2 (IL-2), INF $\vee$ y factor de necrosis tumoral beta (FNT $\beta$ ) (respuesta Th1) necesarios para una inmunidad efectiva contra la ameba. Estudios de Salata reportan muerte en el $92 \%$ de trofozoitos por células T CD8+, que requiere un mecanismo de adherencia secuencial y posterior citolisis, 
estos mecanismos amebicidas de los linfocitos continúan en estudio (47). Así, la activación antígeno-específica de células $\mathrm{T}$, la producción de citoquinas y la actividad efectora de estas células son un componente importante de la inmunidad contra E. histolytica. Sin embargo, se ha evidenciado que durante la infección existe una modulación de su respuesta, evidencia de esto es la reducción de reactividad de reacciones de hipersensibilidad retardada en la fase aguda de la enfermedad. Durante la infección los linfocitos T no proliferan a diversos estímulos (fitohemaglutinina y concavalina A). En adición, existe una relación $\mathrm{CD}^{+}: \mathrm{CD}^{+}$menor que en pacientes no infectados lo cual retarda el desarrollo de inmunidad celular antígeno-específica. Estudios recientes han mostrado una promoción a la producción de linfoquinas respuesta Th2 que conllevan a disminución en la proliferación de células $\mathrm{T}$ y activación inadecuada de macrófagos en respuesta a antígenos amebianos $(3,47)$.

Asimismo, los neutrófilos tienen un papel relevante en la patogénesis del AHA, son la defensa celular más temprana frente a la ameba en el hígado, aparecen una hora luego de la inoculación. La E. histolytica puede lisar los neutrófilos in vitro ocasionando liberación de su contenido, lo que sugiere que parte del daño visto en el absceso hepático proviene de los mediadores liberados por los neutrófilos. Sin embargo, estudios han evidenciado lesiones más grandes en ratones neutropénicos que en ratones normales a los 2 y 4 días luego de la inoculación, sin alcanzar significancia estadística a los 7 días y con ausencia completa del halo inflamatorio alrededor de la región necrótica, probablemente en este momento juegan un papel importante otros tipos celulares para el control de la infección como los macrófagos o linfocitos citotóxicos. Estos estudios muestran el papel de los neutrófilos en la resistencia a la infección y sugieren la capacidad de la E. histolytica en la producción de daño hepático en ausencia de células inflamatorias $(48,49)$.

También se ha visto incapacidad de los neutrófilos para destruir la $E$. histolytica, al parecer ésta escapa a la actividad citotóxica de las moléculas liberadas por los neutrófilos a través de diversas enzimas como la superóxido dismutasas que liga hierro, la oxido reductasa de NADPH-flavina, la oxidasa de NADPH generadora de $\mathrm{H}_{2} \mathrm{O}_{2}$ y otros mecanismos aún no explicados. No hay evidencia de cómo el parásito escapa a las moléculas citotóxicas de los neutrófilos, alternativamente se ha especulado que los neutrófilos presentes en la lesión no se encuentran activados dado que se ha evidenciado su actividad amebicida cuando han sido previamente activados con INF $\gamma_{0}$ FNT $\alpha$. Lo contrario ocurre con la E. dispar contra quienes son altamente efectivos en eliminarla en las primeras 96 horas luego de la inoculación. 
Todo lo anterior indica un papel crítico de los neutrófilos en resistencia temprana al AHA $(30,49)$.

Los eosinófilos, al igual que los neutrófilos y los macrófagos, son destruidos por la E. histolytica in vitro, sin embargo, si los eosinófilos se encuentran activados son amebicidas. Los eosinófilos se encuentran en fases tempranas del AHA en contacto directo con el trofozoito y la presencia de eosinofilia se asocia a protección contra desarrollo de AHA, mientras la presencia de eosinopenia se asocia con mayor mortalidad en estudios experimentales, sugiriendo una participación activa del eosinófilo en la protección de amebiosis invasiva (50).

Experimentos in vitro, han demostrado el papel de diversas citoquinas (INF $\gamma$, FNT $\alpha$ y $\beta$, FEC-1, IL-2 y otras) en la activación de macrófagos y neutrófilos para destruir la E. histolytica. De igual forma, se ha encontrado que el oxido nítrico favorece la resistencia del hepatocito frente a la apoptosis inducida por el parásito, también estimula la regeneración hepática y ocasiona la destrucción del parásito, ésta se considera la principal molécula implicada en la citotoxicidad mediada por los macrófagos frente al trofozoito $(30,51)$. El FNT $\alpha$, producido por macrófagos activados, actúa en forma autocrina aumentando la citotoxicidad contra el parásito al elevar la expresión genética de la oxido nítrico sintetasa inducible (3).

La identidad de las moléculas amebianas involucradas en la modulación de la respuesta inmune del huésped es desconocida. Los receptores y la interacción con estos, las vías de transducción que son usadas y los elementos de regulación genética deben ser elucidados y es probable que más de una molécula se encuentre involucrada. La lectina de adhesión y la proteína rica en serina de la $E$. histolytica tienen efectos inmunoprotectores más que inmunosupresores (3).

Se ha observado mayor susceptibilidad para desarrollar AHA en el embarazo, la Diabetes Mellitus tipo 2, el alcoholismo, la desnutrición con hipoalbuminemia severa y las infecciones crónicas. Se han descrito numerosos reportes de la ocurrencia de amebiosis fulminante, en particular en pacientes con colitis amebiana, en pacientes usuarios de corticoesteroides $(24,25)$. En modelos animales, una disminución en la actividad de la inmunidad celular como en timectomía neonatal, esplenectomía, tratamiento con esteroides, radiación y globulinas antimacrófagos y antilinfocitos están relacionadas con el aumento en el tamaño del absceso hepático amebiano (52). 
Figura 1. Interacción entre E. histolytica, macrófagos, linfocitos T y neutrófilos

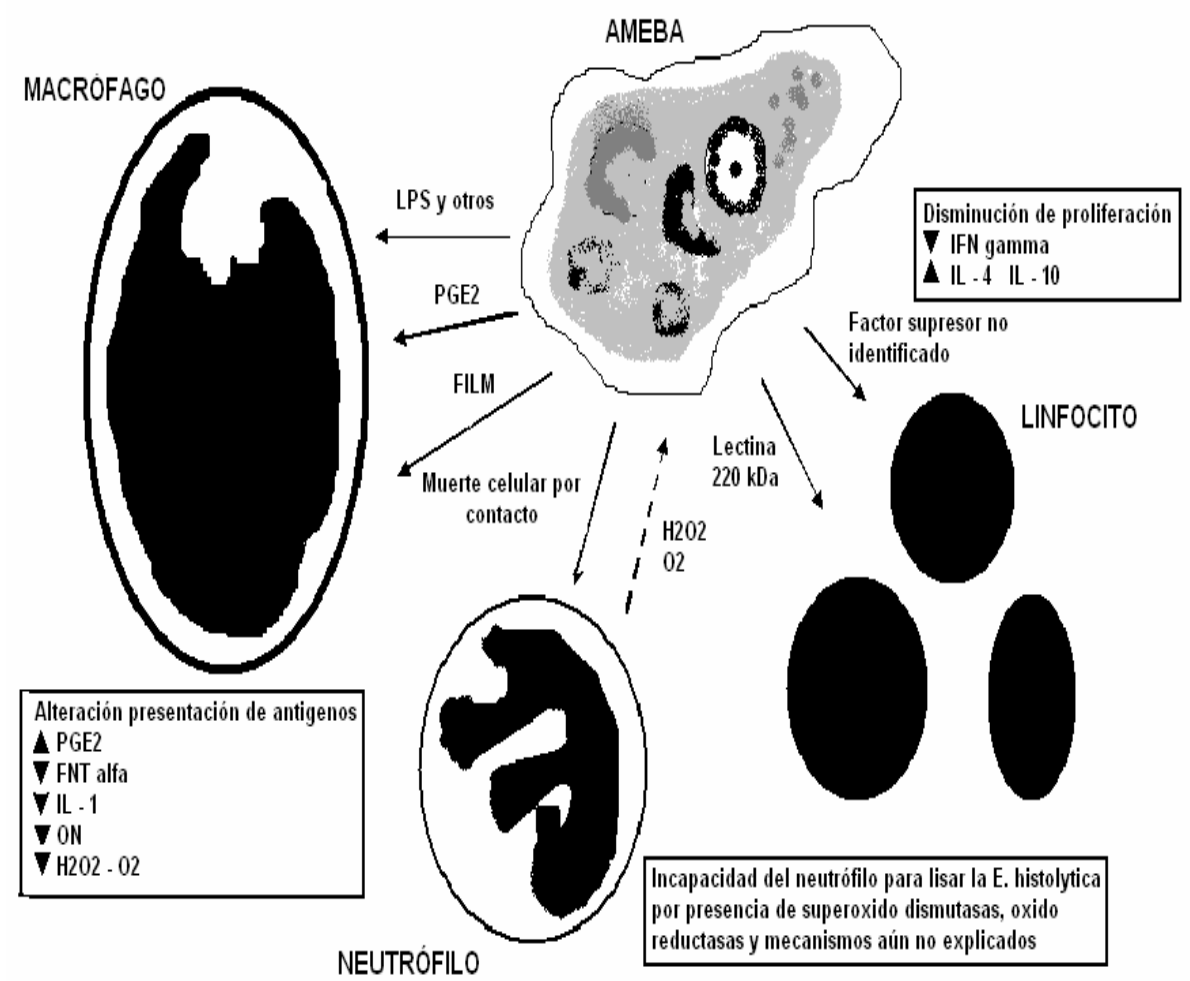

LPS:lipopolisacaridos, FILM:factor inhibidor de la locomoción del monocito, IFN:interferón, FNT:factor de necrosis tumoral, ON:oxido nítrico, IL:interleucina, PGE2:prostaglandina E2

\section{INMUNIZACIÓN}

En animales de experimentación se ha demostrado la resistencia a la formación de AHA cuando han sufrido previamente amebiasis hepática o cuando se han inmunizado con extractos proteicos amebianos. Estos hallazgos concuerdan con observación en humanos de escasa repetición de absceso hepático. 
En estudios realizados en México e India se demostró que la recurrencia de AHA en pacientes seguidos durante 5 años era menor que en la población general (24). Por las observaciones experimentales y clínicas mencionadas, se ha estimulado el interés por el desarrollo de una vacuna. Además, dado que no hay reservorio animal ni vector de E. histolytica, una vacuna efectiva podría eliminar la infección pero el entendimiento incompleto de los mecanismos de inmunidad y patogénesis relacionados con la E. histolytica y la falta de modelos animales para amebiosis asintomática o colitis amebiana, han sido obstáculos para el desarrollo de la misma (9).

Estudios inmunológicos han mostrado que la protección contra la amebiosis se asocia con anticuerpos contra la lectina de adhesión que bloquea la adherencia del trofozoito y su mecanismo de muerte celular por contacto $(28,42)$. Esta es una molécula atractiva para el desarrollo de una vacuna por ser una proteína antigénica presente en E. histolytica aislada de varias zonas geográficas (presente en el $95 \%$ de cepas de cientos de pacientes en varias partes del mundo), es reconocida por el sistema inmune humoral (IgG, IgM e $\operatorname{IgA}$ ), juega un papel importante en la virulencia y estimula la secreción de linfoquinas y linfocitos amebicidas. Animales inmunizados con esta molécula, antes de la infiltración hepática directa con trofozoitos, generan una protección completa contra la formación de AHA en la mayoría de los casos (9). La inmunización con cepas de Salmonella atenuada que expresan esta lectina fue efectiva en la protección contra enfermedad sistémica causada por el trofozoito (53).

En un estudio prospectivo reciente se demostró en niños de Dhaka que presentaban anticuerpos IgA antilectina se asociaba con mecanismo de protección para infecciones futuras presentando $64 \%$ menos infecciones por el parásito comparados con aquellos niños que no los presentaban. Se realizó seguimiento por 12 meses, siendo los 2 grupos significativamente diferentes a los 5 meses $(\mathrm{p}=0,03)$ y a los 7 meses $(\mathrm{p}=0,04)$, sugiriendo que la estimulación de la respuesta inmune en mucosas podría ser protectora $(4,29,54)$. En otro estudio se evaluó la incidencia de infección intestinal por E. histolytica y E. dispar luego de una semana de tratamiento de pacientes con AHA por un periodo de seguimiento de 36 meses. Estos pacientes presentaban una prevalencia alta de $\operatorname{IgA}$ antilectina sérica e intestinal (>85\%) al inicio del estudio y persistió significativa hasta los 18 meses. Luego del tratamiento del AHA, los pacientes fueron altamente inmunes a infección por E. dispar por el periodo de seguimiento pero por problemas metodológicos del estudio no se pudo concluir lo mismo para E. histolytica (55). 
En otros estudios experimentales se ha demostrado que la vacunación con proteína rica en serina, una molécula de superficie de la $E$. histolytica, protege contra la formación de AHA en ratones hasta en un $80 \%$ de los casos, gracias a la inducción de anticuerpos y de la respuesta inmune mediada por células, inclusive en animales inmunodeficientes. Otros estudios han reportado protección del $64 \%$ al $100 \%$. Estudios previos con estrategias de inmunización activa y pasiva sugieren que anticuerpos contra la ameba puede proveer protección contra AHA $(32,56)$.

También se han caracterizado otros antígenos de la E. histolytica que son reconocidos por anticuerpos IgA secretoria en pacientes con AHA, que corresponden a enolasa, ciclofilina, proteína ribosomal L23a, familia de proteínas Hsp70 y péptido rico en ácido glutámico potencialmente útiles para el desarrollo de una vacuna o nuevos métodos diagnósticos (57).

La amebiosis es una enfermedad que se conoce desde hace más de cien años, sus mecanismos patogénicos y la respuesta inmune del huésped se están empezando a dilucidar gracias a los avances tecnológicos de nuestra época. La respuesta celular juega el papel más importante pero no logra controlar adecuadamente la invasión de los trofozoitos gracias a sus factores de virulencia; la respuesta humoral se desarrolla en pacientes con amebiasis invasiva pero no se ha evidenciado ser efectiva para evitar la reinfección con excepción de la IgA secretoria como se demostró en estudios recientes (28, $55)$.

En un mundo perfecto la amebiosis podría ser prevenida con la erradicación de la contaminación fecal de los alimentos y el agua, educación en salud y adecuadas medidas de sanidad. Proveer agua y alimentos seguros para todos los niños y adultos de los países en desarrollo requiere de grandes cambios sociales e inversiones económicas masivas (58) .

Agradecimientos. A Myriam Lucía Navarrete, Universidad Nacional de Colombia y a Angélica Knudson, Instituto Nacional de Salud.

\section{REFERENCIAS}

1. Walsh JA. Problems in recognition and diagnosis of Amebiosis: estimation of the global magnitude of morbidity and mortality. Rev Inf Dis. 1986; 8: 228-238.

2. Thompson JE, Fortalenza S, Verma R. Amebic liver abscess: a therapeutic approach. Rev Inf Dis. 1985; 7: 171-179. 
3. Campbell D, Chadee K. Survival strategies of Entamoeba histolytica: Modulation of cell-mediated immune responses. Parasitol Today. 1997; 13:184-190.

4. Stanley, S. Protective immunity to amebiasis: new insights and new challenge. J Infect Dis. 2001; 184:504-506.

5. Salles J, Moraes L, Costa M. Hepatic amibiasis. Brazilian J Infect Dis. 2003; 7:96-110.

6. WHO Meeting. Amoebiasis and its control. Bull WHO 1985; 63: $417-426$.

7. Cáceres E, Castaño de Romero L, Estupiñán D, López MC, Paez S, Pinilla CA, Santacruz MM. En: Corredor A, Arciniegas E, Hernández CA eds. Parasitismo intestinal. Ministerio de Salud, Instituto Nacional de Salud. Santafé de Bogotá: Instituto Nacional de Salud. 2000; 67-68.

8. Guzmán C, López M, Reyes P, Gómez J, Corredor A, Agudelo C. Diferenciación de Entamoeba histolytica y Entamoeba dispar en muestras de materia fecal por detección de adhesina de E. histolytica mediante ELISA. Biomédica. 2001; 21:167-171.

9. Hughes M, Petri W. Amebic liver abscess. Infect Dis Clin N A. 2000; 14:565-82.

10. Pinilla A, López M, Castillo BC, Murcia M, Nicholls R, Duque S, Orozco LC. Evaluación Clínica, Imaginológica e Inmunológica del Absceso Hepático. Acta Med Colomb. 2002; 27:15-25.

11. Rustgi AK, Richter JM. Abscesos hepáticos piógenos y amebianos. En: Clínicas Medicas de Traducción por Folch A. Clin Med N A. México, Interamericana, S. A. 1989; 4:921-935.

12. Gomersall L, Currie J, Jeffrey R. Amoebiasis: a rare cause of cardiac tamponade. Br Heart J. 1994; 71:368-369.

13. Cano F, Restrepo J. Absceso hepático roto a pericardio. Trib Med. 1977; 55:3234.

14. Vargas R, Gutiérrez O, Arguello M. Análisis de 100 casos de amebiais fatal. Acta Med Colomb. 1986; 11(Suppl): 173.

15. Zengzhun G, Bracha R, Nuchamowitz Y, Cheng-I W, Mirelwon D. Analysis by enzimed-linked in immunosorbent assay and PCR of human liver abscess aspirates from patients in China for Entamoeba histolytica. J Clin Microbiol. 1999; 37:3034-3036.

16. Bruchhaus I, Roeder T, Lotter H, Schwerdtfeger M, Tannich E. Differential gene expression in Entamoeba histolytica isolated from amoebic liver abscess. Mol Microbiol. 2002; 44(4):1063-1072.

17. Pinilla A. Absceso hepático. Trib Med. 1998; 98:151-160.

18. Trissl D. Immunology of Entamoeba histolytica in human and animal host. Rev Infect Dis. 1982; 4:1154-1184.

19. Ximenez C, Leyva O. Moran P, Ramos F, Melendro E. Entamoeba histolytica: antibody response to recent and past invasive events. Ann Trop Med Parasitol. 1993; 87:31-39.

20. Martinez-Palomo A. Amibiasis. Primera edición. Panamericana, México 1989.

21. Ravdin JI. State of the Art .Clinical Article. Clin Infect Dis. 1994; 20:1453-66.

22. Botero D, Restrepo M. Amebiasis. En: Parasitosis Humanas. Cuarta edición. Medellín: Corporación Investigaciones Biológicas; 2003. p. 30-58. 
23. Knobloch J, Mannwailer E. Development and persistence of antibodies to Entamoeba histolytica in patients with amebic liver abscess. Am J Trop Med Hyg. 1983; 4:727-732.

24. Salata R, Ravdin J. Review of the human immune mechanisms direct against Entamoeba histolytica. Rev Infect Dis 1986; 8:261-268.

25. Abioye A, Lewis A, McFarlane H. Clinical evaluation of serum inmunoglobulins in amoebiasis. Immunol. 1972; 23:937-945.

26. Valenzuela O, Ramos F, Morán P, González E, Valadez A, Gomez A, Melendro EI, Ramiro M, Muñoz O, Ximenbez C. Persistence of secretory antiamoebic antibodies in patients with past invasive intestinal or hepatic amoebiasis. Parasitol Res. 2001; 87:849-852.

27. Abd-Alla M, Jackson T, Ravdin J. Serum IgM antibody response to the galactose-inhibitable adherence lectin of Entameoba histolytica. Am J Trop Med Hyg. 1998; 59:431-434.

28. Kelsall B, Jackson T, Gathiram V, Salig S, Vaithilingum M, Pearson RD, Ravdin JI. Secretory immunoglobulin A antibodies to the galactose-inhibitable adherence protein in the saliva of patients with amebic liver disease. Am J Trop Med Hyg. 1994; 51:454-459.

29. Haque R, Ali I, Sack R, Farr B, Ramakrishnan G, Petri W. Amebiasis and mucosal IgA antibody against the Entamoeba histolytica adherence lectin in Bangladeshi Children. J Infect Dis. 2001; 183:1787-1793. http://www.journals.uchicago.edu/JID/journal/issues/v183n12/010162/0101 62.text.html - fn1

30. Espinosa-Cantellano M, Martinez-Palomo A. Pathogenesis of intestinal amebiasis: from molecules to disease. Clin Microbiol Rev. 2002;13:318-331.

31. Abbas AH, Lichtman AH, Pobewr JS. El sistema del complemento. : inmunología celular y molecular. Segunda edición en español. Madrid: McGraw Hill- Interamericana; 1999. p. 349-365.

32. Que X, Reed S. Cysteine proteinases and the pathogenesis of amebiasis. Clin Microbiol Rev. 2000; 13:196-206.

33. Seydel K, Braun K, Zhang T, Jackson T, Stanley S Jr. Protection against amebic liver abscess formation in the severe combined immunodeficient mouse by human anti-amebic antibodies. Am J Trop Med Hyg. 1996; 55:330-332.

34. Kraoul I, Adjmi H, Lavarde V, Pays J, Tourter-Schaefer C, Hennequin C. Evaluation of a rapid enzime immunoassay for diagnosis of hepatic amoebiasis. J Clin Microbiol. 1997; 35:1530-1532.

35. Nicholls R, Restrepo M, Duque S, López M, Corredor A. Standardization and evaluation of ELISA for the serodiagnosis of amoebic liver abscess. Mem Inst Oswaldo Cruz. 1994; 89:53-58.

36. Samrejrongroj P, Tharavanij S. Assesment of validity of counter immuno electrophoresis and ELISA in the routine Diagnosis of amoebiasis. Southeast Asian J Trop Med Public Health 1985; 16:365-370.

37. Gandhi B, Irshad M, Chawla T, Tandon B. Enzyme Linked Protein - A: an ELISA for detection of amoebic antibody. Trans R Soc Trop Med Hyg. 1987; 81:183-185. 
38. Sathar M, Simjee A, Nel J, Bredenkamp B, Gathiram V, Jackson T. Evaluation of an enzyme-linked immunosorbent assay in the serodiagnosis of amoebic liver abscess. S Afr Med J. 1988; 74:625-628.

39. Sathar MA, Bredenkamp BL, Gathiram V, Simjee AE, Jackson TF. Detection of Entamoeba histolytica inmunoglobulins $\mathrm{G}$ and $\mathrm{M}$ to plasma membrane antigen by enzyme-linked immunosorbent assay. J Clin Microbiol. 1990; 28:332-335.

40. Jackson T, Anderson C, Simjee A. Serological differentiation between past and present infection in hepatic amoebiasis. Trans Roy Soc Trop Med Hyg. 1984; 78:342-345.

41. Pinilla AE, López MC, Castillo BC, Morales O, Reyes P, De la Hoz FP, Nicholls RS y Duque S. Estandarización de la prueba de ELISA para la detección de IgM en el diagnóstico de absceso hepático amebiano. Infectio. En: Memorias del IV Encuentro Nacional de Investigaciones en enfermedades Infecciosas. 2004; 82:140.

42. Sathar MA, Bredenkamp B, Gathiram V, Simjee A, Jackson T. Detection of Entamoeba histolytica immunoglobulins $\mathrm{G}$ and $\mathrm{M}$ to plasma membrane antigen by enzyme-linked immunosorbent assay. J Clin Microbiol. 1990; 28:332-335.

43. Haque R, Mollah NU, Ali IK, Alam K, Eubanks A, Lyerly D, Petri WA Jr. Diagnosis of amebic liver abscess and intestinal infection with the TechLab Entamoeba histolytica II antigen detection and antibody tests. J Clin Microbiol. 2000; 38:3235-3239.

44. Haque R, Ali IK, Akther S, Petri WA Jr. Comparison of PCR, Isoenzyme analysis, and antigen detection for diagnosis of Entamoeba histolytica infection. J Clin Microbiol. 1998; 36:449-452.

45. Karki B, Parija S. Co-agglutination test for the detection of circulating antigen in amebic liver abscess. Am J Trop Med Hyg 1999; 60:498-501.

46. Morán P, Rico G, Ramiro M, Olvera O, Ramos F, González E, Valadez A, Uriel $\mathrm{O}$, Melendro EI, Ximenez C. Defective production of reactive oxygen intermediates (ROI) in a patient with recurrent amebic liver abscess. Am J Trop Med Hyg. 2002; 67:632-635.

47. Vohra H, Kaur U, Sharma A, Bhalla V, Bhasin D. Effective human defense against E. histolytica: high amoebicidal activity of lymphocytes and monocytes in amoebic liver abscess patients until 3 months follow-up. Parasitol Int. 2003; 52:193-202.

48. Velásquez C, Shibayama-Salas M, Aguirre-Garcia J, Tsutsumi V, Calderon J. Role of neutrophils in innate resistance to Entamoeba histolytica liver infection in mice. Parasite Immunol 1998; 20:255-262.

49. Seydel K, Zhang T, Stanley SL Jr. Neutrophils play a critical role in early resistance to amebic liver abscesses in severe combined immunodeficient mice. Infect Immun. 1997 65:3951-3953.

50. López-Osuna M, Cárdenas G, Isario J, Arellano J, Fernández-Diez J, Kretschmer R. Increased susceptibility to experimental amebic abscess of the liver (EAAL) in Gerbils (Meriones unguiculatus) with Induced eosinopenia. Arch Med Res. 2000; 31:108-109. 
51. Seydel K, Smith S, Stanley S. Innate immunity to amebic liver abscess is dependent on gamma interferon and nitric oxide in a murine model of disease. Infect Immun.. 2000; 68:400-402.

52. Singh U, Petri W. Amebas en: Principles and Practice of Clinical Parasitology. Jhon Wiley and Sons, LTD 2001:197-218.

53. Mann B, Burkholder B, Lockhart L. Protection in a gerbil model of amebiasis by oral immunization with Salmonella expressing the galactose/N-acetyl Dgalactosamine inhibitable lectin of Entamoeba histolytica. Vaccine. 1997; 15:659-663.

54. Miller-Sims V, Petri W. Opportunities and obstacles in developing a vaccine for Entamoeba histolytica. Curr Opin Immunol. 2002; 14:549-552.

55. Ravdin JI, Abd-Alla M, Welles S, Reddy S, Jackson T. Intestinal antilectin immunoglobulin A antibody response and immunity to Entamoeba dispar infection following cure of amebic liver abscess. Infect Immun. 2003; 71:899-905.

56. Zhang T, Stanley S. DNA Vaccination with the serine rich Entamoeba histolytica protein (SREHP) prevents amebic liver abscess in rodents models of disease. Vaccine. 2000;18: 868-874.

57. Carrero J, Petrossian P, Acosta E, Sanchez-Zerpa M, Ortiz-Ortiz L, Laclette J. Cloning and characterization of Entamoeba histolytica antigens recognized by human secretory IgA antibodies. Parasitol Res. 2000; 86:330-334.

58. Haque R, Huston C, Hughes M, Houpt E, Petri W, Jr. Amebiasis. N Engl J Med. $2003 ; 348: 1565-1573$. 